\title{
Workers' versus Bankers' Europe (II): Policy Externalities and Credibility in EMU
}

\author{
Laura Bottazzi \\ Università Bocconi, IGIER and CEPR \\ Paolo Manasse* \\ Università degli Studi di Milano and IGIER
}

May 7, 1998

\begin{abstract}
In this paper we analyze how the creation a single currency regime changes the strategic relationship between policy makers, both within and across countries. In particular we look at the role of cross-country externalities and lack of commitment.

When labor taxation is excessive, due to terms of trade externalities, the ECB may be tempted to raise inflation above the flexible exchange rate equilibrium in order to induce governments to substitute seignorage for income taxes. Therefore the equilibrium rate of inflation in EMU typically exceeds the flexible exchange rate level. When the ECB cannot credibly commit to inflation, multiple equilibria may arise, where inflation is excessive and labor taxes too low (Workers' Europe), or viceversa, where taxation is excessive and inflation too low (Bankers' Europe). Finally, if the ECB cannot commit to a fixed scheme for redistributing seignorage, the outcome is excess inflation and suboptimal taxation. Both governments anticipate that the ECB will redistribute seignorage in favor of the country with lower tax revenue, and tend to lower tax rates accordingly.
\end{abstract}

JEL Classification: E42, E61, D82

Keywords: EMU, fiscal policy, monetary policy, credibility

*The authors acknowledge financial support from MURST research grant on "Monetary policy in the OECD countries". 


\section{Introduction}

A fundamental change in European monetary institutions is bound to occur in Europe in 1999, with a single money and a single central bank replacing national monetary authorities and currencies. The uncertainty surrounding the new monetary regime has given rise to opposite fears. On the one hand, there is apprehension that inflation and monetary turmoil may be back in Europe under the pressure of deficit-prone countries (Workers' Europe). On the other hand, worsening unemployment rate strengthens the concern about further tightening of fiscal and monetary policy (Bankers' Europe). Is there a rationale for such worries? Are price stability and/or employment at risk in the new monetary regime? The paper addresses these questions.

The growing literature on EMU has so far failed to address a very simple but fundamental question. How will the new regime alter the incentives for policymakers as well as for individuals? The clue to the answer lies in the understanding of what makes a monetary union different with respect to other exchange rate regimes.

A number of authors, taking the lead from Barro-Gordon (1981), have started from the presumption that a single currency regime is synonymous to commitment, see for example Agell, Calmfors and Jonsson (1996) and Brociner and Levine (1992). The standard justification is that an European Central Banker is less likely to bow to pressures from national governments than a nationally appointed governor. Yet, in principle, there is no obvious reason why the Central Bank of a federation of independent states, who share the same currency, should be ipso facto more "independent" than say, the Central Bank of a State who preserves its own money.

Others have assumed a monetary union to be synonymous to a fixed exchange rate regime (see among others Jensen (1994)). Yet we know that monetary unions do not suffer from speculative attacks as opposed to fixed exchange rates (see Obstfeld (1996)).Under fixed exchange rates, pegging the nominal exchange rate implies a redistribution of international reserves and money supplies from the country running a deficit to the country running a surplus in the balance of payments (the so called "rules of the game"). This effect is obviously absent in a monetary union.

Finally, some authors have implicitly identified monetary union with international cooperation in monetary policies, see de Kock and Grilli (1989). But cooperative equilibria are typically "fragile" (that is, they are not Nash, unless 
infinite horizon or reputational considerations are invoked), while a monetary union is, in principle, more difficult to reverse. Moreover, if countries are not identical, cooperation in monetary policies may require different rates of inflation, an option clearly unavailable for a monetary union. More importantly, the working of a monetary union, albeit not that of a fixed exchange rate regime, requires rules for redistributing seignorage.

In a companion paper (Bottazzi and Manasse (1998)), we have addressed the same question (what makes a monetary union different) and we have focused our attention on the informational asymmetries that may arise in a single currency system where national authorities retain the control over fiscal policy. In this paper we study how the creation of a single currency changes the strategic relationship between policy-makers, both within and across countries.

In Section 2 we consider how EMU alters the nature of cross-country spillovers, and how this affects policy incentives. We show that, due to the presence of beggar-thy-neighbor spillovers, the equilibrium rate of inflation is typically higher, and labor tax rates lower, in EMU than in flexible exchange rates. The intuition is as follows. Unlike a regime with national currencies, the EMU works like a one principal (the ECB)-multi-agents (governments) scheme. In the model, the rate of inflation and labor tax rates are strategic substitutes. Governments set labor tax rates inefficiently high, as they neglect the adverse effect of the real exchange rate appreciation on foreign welfare. As a result, the ECB can be tempted to raise inflation (above the flexible exchange rate equilibrium) to induce governments to substitute seignorage for income taxes. Sibert (1992) obtains a similar result, albeit within an overlapping generation framework. In that model the negative externality works through a purely redistributive effect. Domestic taxation reduces savings and money demand, and thus reduces (domestic as well as foreign) seignorage revenue.

In Section 3 we look at the consequences of the change in regime when monetary policy lacks credibility. When the ECB cannot credibly commit to inflation, multiple equilibria may arise, both of the "Bankers' type" (with excessive taxation and suboptimal inflation), as well as of the "Workers' type" (with excessive inflation and suboptimal taxation). Here EMU works like a two-principals (national governments)-one-agent (the ECB) scheme. The following example, based on the idea of self-fulfilling expectations, provides some intuition. Since the (optimal) rate of inflation is a strategic substitute for taxation, the ECB reacts by lowering inflation when tax rates are raised. If the domestic government expects low tax rates abroad, it also expects a lax monetary policy by the ECB. This re- 
duces the optimal tax rate at home. Inflation will then be excessive, and tax rates inefficiently low (Workers' Europe). The same logic applies when the domestic government expect high taxes abroad. In that case a "Bankers'" equilibrium will result. What is crucial here is that in a single currency world, the ECB's lack of commitment to inflation creates an new externality between domestic and foreign fiscal policies.

Finally, we consider the case where the ECB cannot commit to a fixed scheme for redistributing seignorage. Here, the equilibrium always resembles that of the Workers' type. The reason is quite intuitive. Both governments anticipate that the ECB will redistribute seignorage in favor of the country with lower tax revenue, and tend to lower tax rates accordingly.

Section 4 summarizes the main conclusions and policy implications for institutional design.

\section{Externalities}

The aim of this section is to discuss and compare a regime of flexible exchange rates and a Monetary Union when terms-of-trade externalities are at work.

Following van der Ploeg (1988) and Calvo (1978), we develop a two-country general equilibrium model. Here we assume that the Central Bank can enter a binding commitment with respect to national governments. Later we will consider the opposite case where Central Banks cannot commit vis à vis governments.

\subsection{Households}

Consider a world consisting of two countries. Each country (domestic and foreign) is populated by a representative infinite lived agent, and produces only one good by employing labor, $l$, the only (immobile) factor of production. For simplicity, technology is assumed to be linear. Households supply labor, spend their disposable income on both domestic $\left(c^{d}\right)$ and foreign $\left(c^{m}\right)$ goods, which are imperfect substitutes. They save by accumulating domestic money balances $(m)$. There is neither capital nor bonds in the economy, but there exist two distinct national monies, each held exclusively by residents. Governments finance national public goods $g$, by levying distortionary taxes on labor income and by seignorage. For simplicity, we focus on the domestic country.

Preferences are described by an additively separable utility function, where separability is assumed both with respect to time and with respect to the argu- 
ments. Consumers choose the sequence $\left\{c_{t}^{d}, c_{t}^{m}, m_{t+1}, l_{t}\right\}_{t=0}^{t=\infty}$ so as to maximize the present discounted value of their utility stream

$$
\sum_{t=0}^{\infty} \rho^{t} U\left(c_{t}^{d}, c_{t}^{m}, m_{t+1} l_{t}\right)=\sum_{t=0}^{\infty} \rho^{t}\left[u\left(c_{t}^{d}\right)+x\left(c_{t}^{m}\right)+w\left(m_{t+1}\right)+v\left(1-l_{t}\right)+H\left(g_{t}\right)\right]
$$

where $0<\rho<1$ denotes the rate of time preferences, $m_{t+1}$ is the stock of domestic balances carried over from time $t$ to time $t+1$, expressed in units of time $t+1$ home goods. The time endowment has been normalized to unity, while the functions $u, v, w$ and $H$ are well-behaved and quasi-concave. In this section, we focus on the case of a Cobb-Douglas utility:

$U=\exp \left(\alpha \log c^{d}+\beta \log c^{m}+\delta \log (m)+\gamma \log (1-l)+\vartheta \log (g)\right), \alpha+\beta+\delta+\gamma=1$

Consumers spend their labor income in domestic and foreign goods, pay an income tax and an inflation tax on the stock of money balances, and save by adding to their money holdings. Households' budget constraint is therefore

$$
m_{t+1}\left(1+\pi_{t}\right)=m_{t}+\left(1-\tau_{t}\right) l_{t}-\left(c_{t}^{d}+e_{t} c_{t}^{m}\right)
$$

where $e_{t}$ represent the relative price of foreign goods (i.e. units of home goods for one unit of foreign goods: an increase in $e_{t}$ denotes a real depreciation of the domestic currency) $\pi_{t}$ is the domestic rate of inflation between $t$ and $t+1, \tau$ is the labor income tax rate. The real wage is equal to one from the assumption of linear production technology.

The foreign country (denoted by an "*") is identical to the domestic country with $e^{*}=1 / e$.

\subsection{Government}

The government provides public goods and levies taxes on labor income and real balances:

$$
g_{t}=\tau_{t} l_{t}+\mu_{t} m_{t}
$$

where $\mu_{t}$ is the rate of growth of nominal domestic money between $t$ and $t+1$. 


\subsection{Solution}

The model is solved in the Appendix. In the following sections we will make the assumption that policy makers only care about long run welfare of domestic households. Therefore we solve a static, rather than dynamic, game where the policy-makers select constant paths for $\mu$ and $\tau$.

By definition, $m_{t+1}=m_{t}\left(1+\pi_{t}\right) /\left(1+\mu_{t}\right)$ so that in steady state real balances are constant and $\mu=\pi$, i.e. the rate of growth of nominal balances and the rate of inflation coincide. The expression for the equilibrium real exchange rate, in steady state, is given by

$$
e=E(\bar{\tau}, \bar{\pi}, \stackrel{+}{\tau} *, \stackrel{+}{\pi} *)=\left(\frac{(1-\delta)(1-\rho)+\pi^{*}}{(1-\delta)(1-\rho)+\pi}\right)\left(\frac{(1-\tau)(1-\rho+\pi)}{\left(1-\tau^{*}\right)\left(1-\rho+\pi^{*}\right)}\right)
$$

A rise in the domestic rate of inflation or in the income tax rate reduces disposable income and provokes an incipient trade surplus. Equilibrium in the current account (i.e. in the goods market) then requires a real appreciation of the exchange rate. The behavior of domestic households is given by the following expressions:

$$
\begin{gathered}
c^{d}=C^{d}(\bar{\tau}, \bar{\pi})=\frac{\alpha(1-\tau)(1-\rho+\pi)}{(1-\delta)(1-\rho)+\pi} \\
c^{m}=C^{m}\left(\bar{\tau}^{*}, \bar{\pi}^{*}\right)=\frac{\beta\left(1-\tau^{*}\right)\left(1-\rho+\pi^{*}\right)}{(1-\delta)(1-\rho)+\pi^{*}} \\
l^{s}=L\left(^{-/ 0}, \bar{\pi}\right)=1-\left(\frac{\gamma(1-\rho+\pi)}{(1-\delta)(1-\rho)+\pi}\right) \\
m^{d}=M(\bar{\tau}, \bar{\pi})=\frac{\delta(1-\tau)(1-\rho+\pi)}{(1-\delta)(1-\rho)+\pi}
\end{gathered}
$$

An increase in the rate of inflation reduces the demand for money, and, by lowering disposable income, also depresses the demand for home goods. Since leisure is a normal good, the labor supply, and therefore output, is positively related to inflation. The demand for home goods and real balances are decreasing in the domestic tax rate, due to a negative income effect. With Cobb-Douglas preferences, the substitution and income effect in the labor supply cancel out, so 
that $\tau$ does not appear in (2.8). Finally, an increase in the foreign tax and inflation rates crowd out domestic imports by depreciating the real exchange rate.

By substituting (2.6)-(2.9) in the utility function, we obtain an indirect utility function, which summarizes the welfare implication of monetary and fiscal policy:

$$
\begin{aligned}
W\left(\tau, \pi, \tau^{*}, \pi^{*}\right)= & (1-\rho)^{-1}\left(u\left(C^{d}(\bar{\tau}, \bar{\pi})\right)+x\left(C^{m}\left(\bar{\tau}^{*}, \bar{\pi}^{*}\right)\right)+w((M(\bar{\tau}, \bar{\pi}))+\right. \\
& +\left(1-L\left({ }^{-/ 0}, \bar{\pi}\right)\right)+H(G(\stackrel{+}{\tau}, \dot{\pi}))
\end{aligned}
$$

The domestic inflation and income tax rates finance the provision of the public good, but they distort consumption, saving and labor supply decisions. A negative externality is at work here: domestic inflation and tax rates crowd out foreign import, and depress welfare abroad.

In the following sections we assume that policy makers are benevolent and only care about the (long run) welfare of domestic households. We also assume that monetary authorities can enter binding commitments with respect to national governments and households. In Section 3 we remove this hypothesis and consider the consequences of lack of credibility.

The timing of events is described in Figure 1. At stage 1, Central Banks choose the rate of inflation, each taking as given the choice of the other one. Then, fiscal authorities, having observed inflation at home and abroad, choose the respective income tax rate $\tau, \tau^{*}$, given the choice of the other country. Finally, domestic and foreign households choose $c^{d}, c^{m}, l, m$, given policy variables at home and abroad.

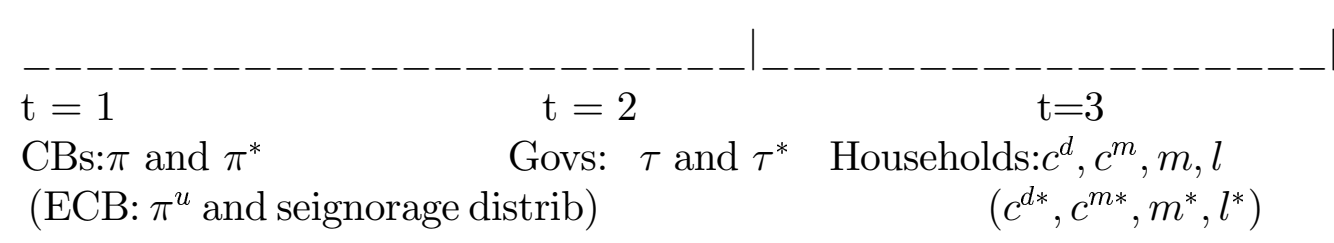

Figure. 1: Timing

\subsection{Flexible Exchange Rates}

In the benchmark regime of flexible exchange rates, there exist two currencies, and monetary policy in each country is run by a national Central Bank. 
The game is solved backward. At stage 2, the domestic government solves

$$
\operatorname{Max}_{\tau} W\left(\pi, \pi^{*}, \tau, \tau^{*}\right) \text { s.t. } \pi, \pi^{*}, \tau^{*}=\text { given }
$$

The first order condition for this problem, $W_{\tau}\left(\pi, \pi^{*}, \tau, \tau^{*}\right)=0$, only depends on domestic policy variables, by virtue of the separable utility function, $W_{\tau}\left(\pi, \pi^{*}, \tau, \tau^{*}\right)=$ $W_{\tau}(\pi, \tau)$. This greatly simplifies the problem, since the domestic government reaction function only depends on domestic monetary policy:

$$
\tau=T(\bar{\pi})=\frac{\vartheta}{\alpha+\delta+\vartheta}-\frac{\delta(\alpha+\delta) \pi}{(\alpha+\delta+\vartheta)(1-\gamma-\delta)(1-\rho-\pi)}
$$

The optimal income tax rate is a decreasing function of the rate of inflation: seignorage and labor taxes are strategic substitutes. The intuition for this result is quite simple. An increase in the rate of growth of money supply has two main effects: i) by raising inflation it raises seignorage revenue. This boosts expenditures on the public good, whose marginal utility falls. As a consequence, the optimal labor tax rate also falls. ii) A higher inflation tax raises the marginal utility of income, and hence it boosts the utility loss associated with a given labor income tax rate. This effect further lowers the optimal labor tax rate.

In the first stage of the game, the domestic Central Bank picks the rate of inflation $\pi$ that maximizes (2.10) taking as given $\pi^{*}$ and the reaction functions of domestic and foreign governments $T(\pi)$, and $T\left(\pi^{*}\right)=\tau^{*}$.

\subsection{Monetary Union}

In EMU individuals in both countries employ the same currency, which is taxed at the same (inflation) rate. With commitment, the ECB acts like a single principal with two agents (the national governments), while in the previous regime we had two principals (the Central Banks) and two agents. The federal monetary policy and the two national tax policies are linked, because seignorage is a common pool of revenue for both governments. The variables $m$ and $m^{*}$ must be interpreted, now, as the demand for the common currency (Euro) by domestic and foreign households, each expressed in terms of home and foreign goods, respectively. We assume that the ECB has two policy instruments: the common rate of inflation and the distribution of seignorage to national governments. The domestic government budget constraint becomes 


$$
g=\tau l+\sigma \pi^{u}\left(m+e m^{*}\right)
$$

where $\pi^{u}$ denotes the common rate of inflation in the monetary union, and $\sigma=1-\sigma^{*}$ is the domestic share of seignorage. The model is solved as in Section 1. It is immediate to verify that the expression for the real exchange rate now becomes

$$
e=\frac{1-\tau}{1-\tau^{*}}
$$

Note that the Monetary Union regime does not eliminate externalities, since these depend on the real, rather than nominal, exchange rates. The common rate of inflation $\pi^{u}$ clearly does not affect the terms of trade anymore, but tax rates do. By comparing the last expression with (2.5), it is immediate to see that this occurs because in EMU the domestic and foreign money growth rates are identical by definition: setting $\pi=\pi^{*}$ in (2.5) yields (2.14). The real exchange rate appreciates following a rise in the domestic income tax rate, or a fall in the foreign tax rates.

We can work out the private sector behavior in terms of the policy variable $\pi^{u}, \tau, \tau^{*}, \sigma$ and obtain the indirect utility function $W^{u}\left(\pi^{u}, \tau, \tau^{*}, \sigma\right)$, as before.

Going back to the second stage of the game, the domestic government chooses the income tax rate, taking $\pi^{u}, \sigma$ and $\tau^{*}$ as given. The optimal tax rate satisfies $W_{\tau}^{u}\left(\pi^{u}, \tau, \tau^{*}, \sigma\right)=0$. This yields the reaction function

$$
\tau=T^{u}\left(\bar{\pi}^{u}, \bar{\sigma}\right)=\frac{\vartheta}{\alpha+\delta+\vartheta}-\frac{2 \sigma \delta(\alpha+\delta) \pi}{(\alpha+\delta+\vartheta)(1-\gamma-\delta)(1-\rho-\pi)}
$$

Similarly to the previous case, the optimal tax rate in EMU, is decreasing in $\pi$. But now, if a country receives a larger share of revenue, it is able to finance public goods by lowering the distortionary tax on labor.

In the first stage, the ECB chooses $\pi^{u}$ and $\sigma$ so as to maximize the joint welfare in the federation,

$$
W^{u}\left(\pi^{u}, T^{u}\left(\pi^{u}, \sigma\right), T^{u}\left(\pi^{u}, 1-\sigma\right), \sigma\right)+W^{u}\left(\pi^{u}, T^{u}\left(\pi^{u}, 1-\sigma\right), T^{u}\left(\pi^{u}, \sigma\right), 1-\sigma\right)
$$

The optimal choice of $\sigma$ is immediate. From the symmetry of the problem, the utility of an additional unit of seignorage is equalized between the two country only for $\sigma=\sigma^{*}=1 / 2$. 
When seignorage is optimally distributed $(\sigma=1 / 2)$, the government reaction function in a Monetary Union, $T^{u}($.$) and in Flexible Exchange rates, T($.$) , coin-$ cide (compare (2.12) and (2.15) for $\sigma=1 / 2$ ). Similarly, households' behavioral equations in FR, expressions(2.6)-(2.9) and EMU coincide, when seignorage is optimally allocated. This follows from the equality between the government budget constraints, cf. (2.4) and (2.13).

It immediately follows that

Lemma 2.1. The equilibrium inflation and tax rates in Monetary Union, where seignorage is optimally chosen, and the equilibrium inflation and tax rates in a Flexible exchange rate regime, where Central Banks cooperate, coincide.

This equivalence makes the comparison between FR and EMU quite easy, since it implies that, provide $\sigma=1 / 2$, it suffices to compare a FR regime with non-cooperative monetary policy with a FR regime with cooperative monetary policy (which replicates EMU).

\subsection{A Numerical Example}

Since analytical results are quite algebra-intensive, we compute the numerical solutions for the FR and EMU regime (and compare it with the second best, where both monetary and fiscal policy are set cooperatively). The main results and the values of parameters are shown in Table 1.

The introduction of a single currency raises inflation, albeit only marginally. The optimal rate of monetary growth rises by roughly one third of a percentage point (from $2.17 \%$ to $2.5 \%$ ), and, as a consequence, tax rates fall by one percentage point (from $56 \%$ in FR to $55 \%$ ). The welfare effect of the change in regime is negligible.

These results are robust with respect to the choice of parameters. The difference between regimes tends to rise, albeit quite slowly, with the value of the parameter $\vartheta$, the relative weight of public goods in the consumers' utility function.

\begin{tabular}{lllll}
\hline & $\pi$ & $\tau$ & $g$ & $W$ \\
$\mathrm{FR}$ & 0.0217 & 0.5656 & 0.3295 & 0.15483 \\
EMU & 0.025 & 0.5555 & 0.3333 & 0.15493 \\
2nd best & 0.0250 & 0.5000 & 0.3125 & 0.15588 \\
parameters values : $\alpha=0.2, \beta=0.2, \gamma=0.4, \delta=0.3, \theta=1, \rho=0.95$
\end{tabular}

Table 1 
The interpretation is as follows. The terms of trade externalities causes inefficiently high tax rates, as it is clear comparing tax rates in FR (and EMU) with tax rates in the second best. Hence, Central Banks (or the ECB in EMU) choose the inflation rate(s) with a view to affect tax policy. In EMU, the marginal benefit from inflation is larger than in FR, since the ECB can obtain a reduction in income tax rates in both countries, while a national Central Bank cannot (the effect is stronger the more $\tau$ and $\pi$ are strategic substitutes). For this reason, when moving from monetary independence to a single currency, inflation tends to rise, and income taxes tend to fall. On the other hand, the marginal cost of inflation in EMU is also higher than in FR. In fact, EMU replicates a situation where monetary policy is set cooperatively (provided seignorage is optimally redistributed). Therefore, the inflation externality is internalized (this effect is larger the larger the weight of imports in consumption), and seignorage tends to fall in EMU. These two effects partially cancel out, so that the change in regime has only small implications for inflation, tax rates and welfare ${ }^{1}$.

In summary, with commitment, EMU improves welfare, since it gives the ECB the right incentives to correct for fiscal externalities. It does so by spurring inflation and inducing governments to cut income taxes. In any case, our computations suggest that the welfare gains and the change in inflation and tax rates are likely to be small.

\section{Credibility}

What if precommitment is not feasible? We consider two cases. In the first, the Central Bank cannot commit to the inflation rate. In the second, the ECB cannot commit to a lump-sum redistribution of seignorage.

We find that lack of commitment with respect to the choice of the inflation rate has no consequences under flexible exchange rates, but may lead to multiple equilibria in EMU, some of characterized by excessive inflation (Worker' Europe), and some by excessive labor income taxation (Banker's Europe). Lack of commitment with respect to the redistribution of seignorage unambiguously leads to excessive inflation in EMU.

In order to focus on these issues, we look at an example that leaves out terms of trade externalities, so that domestic households only consume domestic goods.

\footnotetext{
${ }^{1}$ It can be shown that in a Cobb-Douglas world, the first effect always prevails.
} 
As we shall see, when precommitment is not feasible, EMU creates a new externality between fiscal policies, that accounts both for the potential inefficiency and multiplicity of equilibria.

In order to keep this case tractable, we now assume linear preferences in consumption ${ }^{2}$ :

$$
U=c+w(m)+v(1-l)+H(g)
$$

The private sector first order conditions in steady-state now read ${ }^{3}$ (cf. equations (5.1), (5.3), (5.4) in the appendix)

$$
\begin{aligned}
v^{\prime}(1-l) & =(1-\tau) \\
w^{\prime}(m) & =\pi
\end{aligned}
$$

so that the labor supply, money demand and consumption decisions simplify to

$$
\begin{aligned}
l & =L(\tau), \quad L_{\tau}=1 / v^{\prime \prime}<0 \\
m & =M(\pi), \quad M_{\pi}=1 / w^{\prime \prime}<0 \\
c & =(1-\tau) L(\tau)-M(\pi) \pi
\end{aligned}
$$

which immediately yield the indirect utility function

$W(\pi, \tau)=(1-\tau) L(\tau)-\pi M(\pi)+v(1-L(\tau))+w(M(\pi))+H(\tau L(\tau)+M(\pi) \pi)$

\subsection{Lack of Commitment to Inflation}

The timing of the game now looks like in Figure 2:

\footnotetext{
${ }^{2}$ This specification has the advantage of ruling out the income effect in the labor supply. In the previous sections due to the the logarithmic utility function, the income and substitution effect cancelled out. This enabled us to focus on the terms of trade externality

${ }^{3}$ We set $\rho=1$ to simplify notation
} 


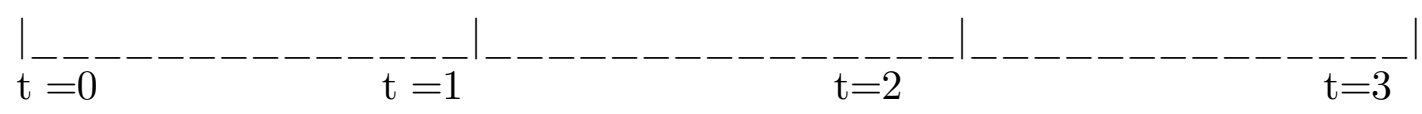

$\begin{array}{lll}\left(\sigma \text { is chosen) Govs: } \tau\left(\text { and } \tau^{*}\right)\right. & \text { (E)CBs: } \pi, \pi^{*} \text { Households: } c, m, l\end{array}$

Figure. 2: Lack of commitment with respect to $\pi$

To begin with, we assume that a $t=0$, in EMU, the two countries agree to share seignorage, and we postulate that $\sigma=1 / 2{ }^{4}$.

We discuss this assumption in Section 3.2.

\subsubsection{Flexible Exchange Rates}

At $\mathrm{t}=2$, the domestic Central Bank chooses $\pi$, given $\tau$, so as to maximize (3.7). The first order condition can be written as

$$
H_{g}(\tau L(\tau)+M(\pi) \pi)=\frac{1}{1-\varepsilon(\pi)},
$$

where $\varepsilon(\pi) \equiv-M_{\pi}(\pi) \pi / M$ is the elasticity of money demand. This condition simply equates the marginal rate of substitution between private and public consumption (the lhs) to the marginal rate of transformation (the rhs). Clearly, for a given $\pi$, the more elastic is the demand for money, the more distortionary is the inflation tax, and the lower is the optimal inflation rate ${ }^{5}$. Similarly, in the first stage, the domestic government chooses $\tau$, given the Central Bank reaction function (3.8). From the envelope theorem this yields

$$
H_{g}(\tau L(\tau)+M(\pi) \pi)=\frac{1}{1-\eta(\tau)}
$$

where $\eta(\tau)=-\tau L_{\tau} / L$ represent the elasticity of the labour supply to the income tax rate. The FR equilibrium tax and inflation rates, $\left(\pi^{f}, \tau^{f}\right)$ are the solution of the last two equations. These imply that $\pi^{f}, \tau^{f}$ should be set so as to equalize distortions across tax bases, $\varepsilon\left(\pi^{f}\right)=\eta\left(\tau^{f}\right)$. Note that since the two countries

\footnotetext{
${ }^{4}$ The statute of the ECB states that seignorage must allocated to members according to a fixed rule based on members' relative population size.

${ }^{5}$ For the second order condition to be satisfied it is sufficient that the elasticities $\varepsilon(\pi)$ and $\eta(\tau)=-\tau L_{\tau} / L$ be increasing in their respective tax rates,as we assume.
} 
are identical and there are no externalities between them, this equilibrium is symmetric, i.e $\tau=\tau^{*}=\tau^{f}, \pi=\pi^{*}=\pi^{f}$.

Under FR, the strategic relationships (who moves first) between policy authorities is irrelevant, since the optimal monetary and fiscal policies will always satisfy (3.8)-(3.9), which define the second best. Hence in this benchmark case, the lack of pre-commitment of the central bank vis à vis the government is irrelevant. Next we show that, on the contrary, lack of pre-commitment to inflation may have major implications in EMU.

\subsubsection{Monetary Union}

In the second stage the ECB chooses the common rate of inflation in order to maximize the level of joint welfare, $W(\pi, \tau)+W\left(\pi, \tau^{*}\right)$, given $\sigma=1 / 2, \tau$ and $\tau^{*}$. This yields

$$
\frac{1}{2}\left[H_{g}(\tau L(\tau)+M(\pi) \pi)+H_{g *}\left(\tau^{*} L\left(\tau^{*}\right)+M(\pi) \pi\right)\right]=\frac{1}{1-\varepsilon(\pi)}
$$

From this expression it is immediate to derive the optimal choice of inflation, as a function of the labor tax rates:

$$
\pi=\Pi^{e}\left(\bar{\tau}, \bar{\tau}^{*}\right), \quad \Pi_{\tau}^{e}, \Pi_{\tau^{*}}^{e}<0
$$

The optimal inflation rate in EMU depends negatively on income tax rates, that is to say, monetary policy is again a strategic substitute for tax policies.

At $t=1$, the domestic government chooses the income tax rate $\tau$ so as to maximize the welfare function (3.7), subject to the ECB reaction function $\Pi^{e}\left(\tau, \tau^{*}\right)$, and for given $\sigma=1 / 2$ and $\tau^{*}$. After some manipulations, the first order condition for the optimal income tax rate in EMU can be written as follow:

$$
\begin{aligned}
& H_{g}\left(\tau L(\tau)+M\left(\Pi^{e}\left(\tau, \tau^{*}\right)\right) \Pi^{e}\left(\tau, \tau^{*}\right)\right) \\
= & \frac{1}{1-\eta}\left(1-\frac{(\varepsilon(\pi)-\eta(\tau)) \omega \phi}{1-\eta-\omega \phi(1-\varepsilon)}\right)
\end{aligned}
$$

where $\omega\left(\Pi^{e}\left(\tau, \tau^{*}\right), \tau\right)=\pi M / \tau L>0$ represents the ratio between revenues from seignorage and income taxes, and $\phi\left(\tau, \tau^{*}, \Pi^{u}\left(\tau, \tau^{*}\right)\right)=-\Pi_{\tau}^{e}\left(\tau, \tau^{*}\right) \tau / \Pi^{e}\left(\tau, \tau^{*}\right)>$ 0 is the elasticity of the rate of inflation (chosen by the ECB) to the income tax rate (chosen by the domestic government) ${ }^{6}$

\footnotetext{
${ }^{6}$ The denominator of the ratio in the rhs can be shown to be positive from the F.O.Cs .
} 
Equation (3.12) implicitly defines how the domestic government reacts to fiscal policy abroad, $\tau=Y\left(\tau^{*}\right)$. The expression shows a crucial property of a single currency regime: lack of credibility by the ECB introduces a new externality between domestic and foreign fiscal policies, since each government anticipates that the rate of inflation will also depend on the other government's fiscal stance. This contrasts with the case of FR, where foreign tax rates do not affect domestic fiscal policy, and where lack of commitment to inflation has no consequences. By contrast, in EMU the optimal domestic tax rate depends on the foreign tax rate.

What does the reaction curve look like? Consider the following thought experiment. Suppose that, initially, $\varepsilon(\pi)-\eta(\tau)=0$ in (3.12), and consider the effect of a discrete fall in the foreign tax rate $\tau^{*}$. The ECB reacts by raising inflation, and this affects the domestic economy in two ways. On the one hand, as revenue from seignorage rises, the supply of the public good is boosted. Its marginal utility falls, and this reduces the optimal domestic tax rate. This income effect tends to produce "upward sloping" reaction functions. On the other hand, as inflation rises, the demand for money becomes relatively more elastic, since $\varepsilon_{\pi}>0$, and, at the initial tax rate $\tau$, the term $\varepsilon-\eta$ becomes positive. This means that the labor supply becomes relatively more inelastic, so that the government optimally raises $\tau$. This substitution effect tends to produce a downward sloping reaction curve $Y\left(\tau^{*}\right)$. In summary, the reaction curve is negatively sloped provided that the substitution effect prevails on the income effect (see expression(5.16) in the Appendix).

An equilibrium in the EMU regime is defined as a set of policy variables, $\tau^{e}, \tau^{* e}, \pi^{e}$, such that, given the policy function of the ECB, $\Pi^{e}($.$) , each government$ responds optimally to the tax rate of the other government, $\tau^{e}=Y\left(\tau^{* e}\right), \tau^{e *}=$ $Y\left(\tau^{* e}\right)$, and $\pi^{e}=\Pi^{e}\left(\tau^{e}, \tau^{* e}\right)$.

It is simple to show that

Lemma 3.1. Provided the EMU equilibrium is symmetric (and $\sigma=1 / 2$ ), it coincides with the FR equilibrium, i.e $\tau^{e}=\tau^{* e}=>\tau^{e}=\tau^{f}, \pi^{e}=\pi^{f}$

Proof. This follows by inspection of the relevant F.O.C's. If the EMU equilibrium is symmetric, equation (3.10) coincides with (3.9). So the system of equations (3.10)-(3.8) that defines the equilibrium in EMU is identical with the F.O.Cs of the FR solution, (3.9) - (3.8).

The relevant question to ask at this point is whether there may exist other (asymmetric) equilibria in the EMU regime, in addition to the second best. As it 
is often the case with externalities, we cannot rule out this outcome. ${ }^{7}$

When the substitution effect prevails, and condition (5.16) in the Appendix holds, reaction curves are downward sloping (see Figure 1). In this case, in addition to the FR equilibrium, we may have asymmetric multiple equilibria, where monetary integration leads to fiscal divergence. The intuition for this result is the following. Expectations of high labor taxation abroad leads to low anticipated inflation. As money demand becomes relatively inelastic relative to labor supply, the domestic government lowers income taxes. Similarly, if the foreign government expects low income tax rate at home it finds optimal to raise $\tau^{*}$, fulfilling expectations. The equilibrium is in A where the outcome for inflation is ambiguous.

In the opposite case of strong income effect and upward sloping reaction functions (see Figure 2), the FR outcome is still a possible outcome, but other equilibria cannot be ruled out: one equilibrium (or more) may be such that the two countries levy inefficiently low income taxes, and inflation is correspondingly excessive, as in point W (Workers' Europe). Another may be such that governments rely excessively on income taxes, so that inflation is inefficiently low, as in point B (Bankers' Europe). Clearly, from a welfare point of view all these EMU equilibria are dominated by the FR equilibrium, since the latter coincides with the second best $^{8}$.

So far we reached the following conclusion. The move to a single currency system creates a common pool (seignorage) of resources. As a result, when the ECB cannot commit to inflation, the optimal domestic fiscal policy depends on foreign policy. This increased interdependence potentially widens the range of equilibrium outcomes, by adding inefficient equilibria. While Central Banks lack of commitment to inflation has no consequences under flexible rates, lack of credibility is potentially much more damaging in EMU, even assuming identical countries.

\subsection{Lack of Commitment to Seignorage Redistribution}

Suppose now that the ECB commitment to inflation can be taken for granted, so that $\pi$ is mandatorily fixed. But assume that the European Central Bank, rather then giving up any active intervention policy, may be tempted to use the other instrument at her disposal, the redistribution of seignorage, $\sigma$.

\footnotetext{
${ }^{7}$ We could not find any plausible restriction that ensures that the sufficient condition for unicity, $Y_{\tau *}<1$ is satisfied.

${ }^{8}$ Note that our postulated value $\sigma=1 / 2$ is indeed optimal, whenever the equilibrium is symmetric
} 
The sequence of the game now looks like this:

\begin{tabular}{lccc}
\hline $\mathrm{t}=0$ & $\mathrm{t}=1$ & $\mathrm{t}=2$ & $\mathrm{t}=3$ \\
$\mathrm{ECB}: \pi$ & Govs: $\tau\left(\right.$ and $\left.\tau^{*}\right)$ & ECBs: $\sigma$ & Households: $c, m, l$
\end{tabular}

Figure 3: Lack of commitment with respect to $\sigma$

It is easy to show that the lack of commitment with respect to $\sigma$ leads to excessive inflation. The reason is simply that, at $t=1$, each government correctly anticipates that the ECB's optimal policy at $t=2$ is to redistribute seignorage in favor of the country with less tax revenue. Hence it will tend to lower its tax rate in order to substitute seignorage for labor taxation. Clearly these attempts cancel out in equilibrium and lead to excessive inflation and inefficiently low income taxes ${ }^{9}$.

At $\mathrm{t}=2$, the ECB chooses $\sigma$ so as to maximize the joint welfare $W(\pi, \tau, \sigma)+$ $W\left(\pi, \tau^{*}, 1-\sigma\right)$, given the tax rates and the mandatory inflation rate. The f.o.c for this problem is

$$
H_{g}(\tau L(\tau)+2 \sigma M(\pi) \pi)=H_{g *}\left(\tau^{*} L\left(\tau^{*}\right)+2(1-\sigma) M(\pi) \pi\right)
$$

The ECB allocates seignorage to equate the marginal utility of public goods across countries. This requires that domestic and foreign total revenues to be equalized, which can be achieved by setting

$$
\sigma=\frac{1}{2}+\frac{\tau^{*} L\left(\tau^{*}\right)-\tau L(\tau)}{2 M(\pi) \pi}=S\left(\bar{\tau},{\bar{\tau}^{*}}^{*}\right)
$$

If both countries choose the same tax rate, the optimal division of seignorage is one half each. The ECB rewards the country with lower tax rate and revenue, by compensating him with a higher share of seignorage. When the ECB cannot commit to a fix share of redistribution, both governments will anticipate that the rule (3.14) will be followed, ex post. Therefore, they will try to reduce their tax rate below the one of their opponent, in order to appropriate more seignorage, and reduce distortions in the labor market. It follows that

\footnotetext{
${ }^{9}$ The issue of redistribution and credibility is extensively discussed in Bordignon, Manasse and Tabellini(1996)
} 
Lemma 3.2. The unique EMU equilibrium when the ECB cannot pre-commit with respect to the distribution of seignorage is such that a) tax rate are driven down to zero, $\left.\tau^{e}=\tau^{e *}=0, b\right)$ seignorage is equally redistributed, $\sigma^{e}=1 / 2$, and c) inflation in EMU exceeds inflation in $F R, \pi^{e}>\pi^{f}$

\section{Proof.}

Substitute the ECB's reaction function $S($.$) into domestic welfare. This yields$

$$
\begin{aligned}
& W\left(\tau, \tau^{*}, S\left(\tau, \tau^{*}\right), \pi\right)= \\
= & (1-\tau) L(\tau)-\pi M(\pi)+v(1-L(\tau))+w(M(\pi))+H\left(\tau^{*} L\left(\tau^{*}\right)+M(\pi) \pi\right)
\end{aligned}
$$

Part a) follows immediately from differentiation of $(3.15), W_{\tau}()=.-L(\tau)<$ 0 , all $\tau, \tau^{*}$. In turn (3.14) implies that $\sigma^{e}=1 / 2$ when the tax rates are equal. Finally, consider that, from a), the rate of inflation in EMU is defined as follows:

$$
\pi^{e}=\arg \max (W(0,0,1 / 2, \pi)+W(0,0,1 / 2, \pi))
$$

Hence, it satisfies

$$
H_{g}(\pi M(\pi))=\frac{1}{1-\varepsilon(\pi)}
$$

Part c) of the Lemma follows immediately by comparing this expression with (3.8) and recalling $\varepsilon_{\pi}(\pi)>0$.

In summary, the change in regime has strong implications when monetary authorities cannot precommit. When promises to adhere to a pre-announced rate of inflation or to a lump-sump redistribution of seignorage are not credible, multiple and/or inefficient equilibria may arise in EMU. The reason is that this regime creates an externality between fiscal policies that is absent under flexible rates. When inflation promises are not credible, these equilibria may have too much or too little inflation, too low or too high tax rates, and may imply either fiscal convergence or divergence. Similarly, the inability to commit to lump-sum redistribution of seignorage, and the temptation to redistribute in favor of the country with less revenue, provokes excessive inflation and suboptimal taxation. 


\section{Discussion and Conclusions}

In this paper we have analyzed how strategic relationships among policy-makers change in a single currency area.

When looking at externalities across countries, and assuming commitment, the new regime improves welfare, since it gives the ECB the right incentives to correct for fiscal externalities. This is because EMU replicates monetary cooperation, provided that seignorage is optimally redistributed in a lump sum fashion. This is "good news". However, when the externality at work produces excessive taxation of labor, as in our example, this effect implies that EMU is likely to spur inflation. In any case, our computations suggest that the welfare gains and the change in inflation and labor tax rates associated with this externality effect are likely to be small.

This result obviously depends on the sign of the spillover between national fiscal policies. In our first example, labor tax rates are excessive as a consequence of the negative terms of trade externality. Similar conclusions, however, would hold in a model with mobile capital and immobile labor. Here, excessive labor taxation would result from the different mobility of the tax bases, rather than from the terms of trade externality, but the results would remain very much the same.

The "bad news" is that EMU amplifies the inefficiencies associated with lack of credibility in monetary policy. In our second example, lack of commitment to inflation creates a new externality between domestic and foreign fiscal policies. The domestic tax rate affects the common monetary policy and seignorage, and thus the foreign tax policy. As a result, the monetary union widens the range of equilibrium outcomes. Inefficient asymmetric equilibria, such as Workers' Europe (excessive inflation and suboptimal taxation) and Bankers' Europe (excessive labor taxation and deflation) become possible. Furthermore, equilibria may also occur where monetary convergence produces fiscal divergence. Our analysis also shows that EMU does not preclude the possibility of attaining the second best. The policy implication of this is quite clear: in EMU fiscal coordination and cooperation become essential for avoiding "bad equilibria". This argument does not depend upon potential "asymmetries" of shocks, as in the textbook case, but relies entirely on the incentives of the new monetary regime.

Finally, a single currency area introduces another dimension to the credibility problem: the lack of commitment to the redistribution of seignorage. If the ECB is tempted to redistribute in favor of the country with less revenue, governments, 
anticipating this behavior, will try to appropriate seignorage by lowering the income tax rates. As tax rates are driven down (to zero in the model), a Workers' type equilibrium of the worst kind results.

This outcome is similar to the standard tax competition effect, whereby governments drive tax rates down in the attempt to attract firms and capitals. In our setup, however, this occurs as the result of two peculiarities of the EMU regime: i) a monetary union creates a common pool of resources (seignorage) that can be appropriated by national tax policies, and ii) the ECB cannot commit to lump sum redistribution of seignorage. This result reinforces the need for providing "credibly fixed" rules for the distribution of seignorage. To avoid perverse incentive effects, seignorage must be allocated on the basis of fixed parameters that are "truly" exogenous and not manipulable by national governments.

Summing up, as long as an excessive share of the tax burden falls on labor, as result of international spillovers, then EMU generates the right incentives to correct these inefficiencies. However, in the absence of fiscal coordination and lump sum redistribution of seignorage, credibility problems may be seriously aggravated in the new monetary regime, so that the dangers of going "too far" in the direction of loose fiscal policy and inflation should not be dismissed. 


\section{Appendix}

\subsection{The model}

Solving the utility maximization program (2.1) subject to the constraint (2.3), the first order conditions are given by ${ }^{10}$ :

$$
\begin{aligned}
u_{c_{t}^{d}}(.) & =\lambda_{t} \\
x_{c_{t}^{m}}(.) & =e_{t} \lambda_{t} \\
v_{l_{t}}(.) & =\left(1-\tau_{t}\right) \lambda_{t} \\
w_{m_{t+1}}(.) & =\lambda_{t}\left(1+\pi_{t}\right)-\rho \lambda_{t+1} \\
\lim _{T \rightarrow \infty} m_{T+1}\left(\prod_{i=0}^{T}\left(1+\pi_{i}\right)\right) & =0
\end{aligned}
$$

where $\lambda_{t}$ is the multiplier on the constraint (2.3) and equation (5.4) is a standard arbitrage condition that assures that no gains can be made by re-allocating consumption over time. Finally, (5.5) rules out Ponzi games.

From these expressions we can solve for $c_{t}^{d}, c_{t}^{m}, l_{t}$ in terms of $\lambda_{t}$,

$$
\begin{aligned}
c_{t}^{d} & =C^{d}\left(\bar{\lambda}_{t}\right)=\alpha / \lambda_{t} \\
c_{t}^{m} & =C^{m}\left(e_{t} \bar{\lambda}_{t}\right)=\beta / \lambda_{t} e_{t} \\
l_{t} & =L\left((1-\tau) \bar{\lambda}_{t}\right)=1-\gamma / \lambda_{t}(1-\tau)
\end{aligned}
$$

where the sign above a variable denotes the sign of the derivative with respect to that variable. The multiplier $\lambda_{t}$ denotes the marginal value of income. When $\lambda_{t}$ falls the demand for leisure, home and foreign goods rise. Also, an increase in the tax rate on labor reduces net earnings and lowers the labor supply. Finally, domestic imports fall when the real exchange rate depreciates.

The equilibrium in the goods market requires in each period the equality between supply and demand of home goods (by the government, domestic and foreign households (exports)) :

$$
C^{d}\left(\lambda_{t}\right)+C^{m *}\left(\lambda_{t}^{*} / e_{t}\right)+g_{t}=L\left(\left(1-\tau_{t}\right) \lambda_{t}\right)
$$

Together with households and government budget constraints, this condition insures that the trade balance must always be in equilibrium :

\footnotetext{
${ }^{10}$ The index below each function denotes a derivative.
} 


$$
e_{t} C^{m}\left(e_{t} \lambda_{t}\right)=C^{m *}\left(\lambda_{t}^{*} / e_{t}\right)
$$

The optimal (closed loop) monetary and tax policies are found by maximizing the welfare subject to the private sector' first-order conditions (5.1)-(5.4). To avoid the possibility of time inconsistent plans, ${ }^{11}$ we assume that governments give up policy surprises and choose among constant, steady-state paths for $\mu$ and $\tau$. Setting $\lambda_{t}=\lambda$ all $t$ in (5.4), we can solve for the money demand equation:

$$
m_{t+1}=M\left(\bar{\lambda}\left(1+\pi_{t}-\rho\right)\right), M_{\lambda\left(1+\pi_{t}-\rho\right)}=1 / w_{m m}<0
$$

The demand for money depends negatively on the nominal interest rate ${ }^{12}$, and positively on income. In steady state, real balances as well as inflation are constant, as equation (5.11) shows. Re-writing $m_{t+1}=\frac{M_{t+1}}{P_{t+1}}$ in terms of $\mu$ and $\pi$, $m_{t+1}=m_{t}\left(1+\pi_{t}\right) /\left(1+\mu_{t}\right)$, we see that inflation rises one to one with monetary growth in steady state, i.e. $\pi=\mu$ in the long run.

In order to solve for the real exchange rate we can use the condition for balanced trade (5.10), that gives

$$
e=E\left(\bar{\lambda}, \dot{\lambda}^{*}\right)=\lambda^{*} / \lambda
$$

A fall in domestic income (a rise in $\lambda$ ) reduces the demand for imports, leading to a trade surplus. This requires an appreciation of the real exchange rate to restore trade balance.

Since $E\left(\bar{\lambda}, \vec{\lambda}^{*}\right)$ is homogeneous of degree zero in $\lambda$ and $\lambda^{*}$

$$
C^{m *}\left(E\left(\bar{\lambda}^{+}, \dot{\lambda}^{*}\right) \lambda\right)=C^{m *}(\lambda)
$$

Now substitute the consumption and import functions (5.6)-(5.7), together with the government budget constraint (2.4) into the goods market equilibrium(5.9)

$$
C^{d}(\lambda)+C^{m *}(\lambda)+\pi M\left(\left(1+\pi_{t}-\rho\right) \lambda\right)=L\left(\left(1-\tau_{t}\right) \lambda\right)
$$

\footnotetext{
${ }^{11}$ It is well known that this kind of dynamic problem results in time inconsistent plans, since the government has an incentive to re-optimize at a later date and set the private sector's marginal utility of income $\lambda_{t}=0 \quad t>0$ (see Basar and Oldser ( ))

${ }^{12}$ Let $\rho=1 /(1+r)$, where $r$ denotes the real interest rate, and $(1+i)=(1+\pi)(1+r)$. Then $1+\pi_{t}-\rho=i \rho$
} 
This yield the marginal utility of income as a function of the labor tax rate and of the rate of growth of money balances:

$$
\lambda=\Lambda(\stackrel{+}{\tau}, \stackrel{+}{\pi})=\frac{(1-\delta)(1-\rho)+\pi}{(1-\tau)(1-\rho+\pi)}
$$

An increase in the tax rate and in the rate of inflation causes an excess demand for domestic goods, by raising government spending. Hence, from equilibrium in the goods market to be restored, the marginal utility of income must increase so as to convince households to cut their demand.

The last equation can be substituted back in expressions (5.6)-(5.8) and (5.11)(5.12) to express the terms of trade, the demand for home, foreign goods, the labor supply and the money demand in terms of the policy variables. This gives equations (2.5) and (2.6)-(2.9) in the text.

\subsection{The slope of the reaction function of the fiscal authorities in a monetary union}

By totally differentiating equation(3.12) we find $d \tau / d \tau^{*}<0$ iff

$$
\begin{aligned}
& -H_{g g} \Pi_{\tau^{*}}^{e}(1-\varepsilon) M\left(L(1-\eta)+M(1-\varepsilon) \Pi_{\tau}^{e}\right)+M\left[H_{g}(1-\varepsilon)-1\right]\left(\Pi_{\tau \tau *}^{e}-\Pi_{\tau}^{e} \Pi_{\tau^{*}}^{e} \frac{\varepsilon}{\pi}\right) \\
< & H_{g} \varepsilon_{\pi} \Pi_{\tau}^{e} \Pi_{\tau^{*}}^{e}
\end{aligned}
$$

The first term on the lhs is simply the effect of a unit fall in the foreign tax rate on the domestic revenue from seignorage, and hence on the marginal utility of the public good ${ }^{13}$.This is the income effect. Since $\Pi_{\tau}^{e}<0$, provided the crossderivative $\Pi_{\tau \tau *}^{e}$ is negative ${ }^{14}$, the second addendum on the left reinforces the first one, when the public good is over-supplied $\left(H_{g}(1-\varepsilon)<1\right)$, and conversely weakens it when it is under-supplied $\left(H_{g}(1-\varepsilon)>1\right)$ with respect to the FR-second best $\left(H_{g}(1-\varepsilon)=1\right) .^{15}$

The rhs describes the substitution effect. Whenever the foreign tax rate is reduced, the ECB raises inflation, and the domestic money demand becomes more elastic. Therefore the optimal labor tax rate rises. Hence the reaction function $\tau=Y\left(\tau^{*}\right)$ is negatively sloped provided the last inequality is satisfied .

\footnotetext{
${ }^{13}$ This term is always positive from the F.O.C.'s.

${ }^{14} \mathrm{It}$ is easy to show that $\Pi_{\tau \tau *}$ has the opposite sign of $H_{g * g * g *}$ which we assume to be less or equal tozero

${ }^{15}$ In any case, this term vanishes in the FR equilibrium.
} 


\section{References}

Agell, J. L.Calmfors and G.Jonsson,(1996) "Fiscal Policy when Monetary policy is tied to the must", European Economic Review

Barro,Robert J. and David Gordon (1983) " A Positive Theory of Monetary Policy in a Natural rate Model", Journal of Political Economy 91,4

Basar,T. and G.T.Olsder (1982),"Dynamic Non-Cooperative Game Theory", Academic Press,New York

Bordignon,M., P.Manasse and G.Tabellini (1996),"Optimal Regional Redistribution under Asymmetric Information", CEPR Discussion Paper n.1437

Bottazzi , L. and P.Manasse,(1998) "Bankers' versus Workers' Europe (I): Adverse Selection in EMU", CEPR Working Paper, n. 1846.

Brociner, A. and Paul Levine,(1902) "Fiscal Policy Coordination and EMU: a Dynamic Game Approach" CEPR working Papern.639

Calvo,G.A. (1978)," On the Time Consistency of Optimal Policy in a Monetary Economy", Econometrica,46

de Kock,G. and V. Grilli (1989), "Endogenous Exchange Regime switches", NBER W.P.3066

Jensen, H.,(1994) "Loss of monetary discreton in a simple dynamic Policy Game",Journal of Economic Dynamics and Control 18

Obstfeld M.(1996),"Models of Currency Crises with Self-fulfilling features",European Economic review 40, April

Sibert,A.(1992),"Government Finance in a Common currency Area", Journal of International Money and Finance

van der Ploeg,F. (1988),"'International Policy Coordination in Interdependent Monetary Economies", Journal of International Economics, 23, p.1-23 

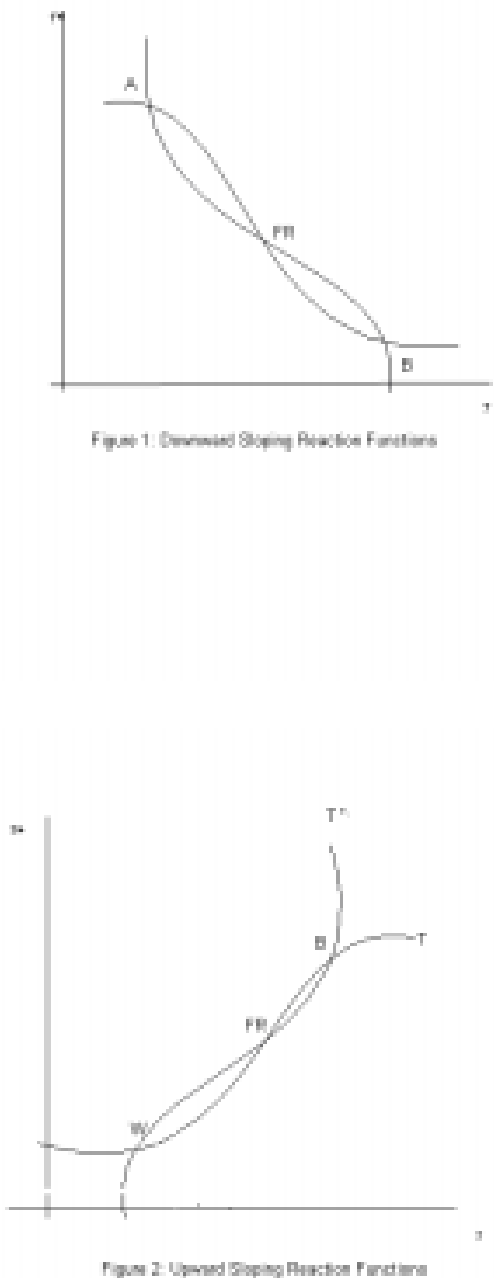